\title{
Renal Adysplasia in Fetus: A Rare Autopsy Case Report
}

\author{
Rashmi K. Patil, Bhumika J. Bhandari* and Shreekant K. Kittur \\ Belagavi Institute of Medical Sciences, Belagavi, Karnataka, India
}

\begin{abstract}
Renal adysplasia is rare, occurring in only one per 10,000 births. Ultrasonography at 21 weeks of gestation in 33 years woman showed cystically enlarged left kidney in fetus and absent right kidney in fetus for which the pregnancy was terminated. On fetal autopsy, left kidney showed multiple tiny cysts. Microscopy of the left kidney showed features of dysplasia and confirmed the absence of right kidney and bilateral ureters. The diagnosis of renal adysplasia (multicystic dysplasia of left kidney and agenesis of right kidney) was made. This case is presented for its rarity.
\end{abstract}

Keywords: Adysplasia, Agenesis, Multicystic, Renal.

\section{Introduction}

Renal adysplasia is defined as unilateral renal agenesis in association with dysplasia of the contralateral kidney. The term adysplasia is often used more broadly to include dysplasia, absent kidneys, and almost any other structural or positional kidney/ lower urinary tract defect. ${ }^{[1]}$ We report a case of renal adysplasia with a combination of multicystic dysplasia of left kidney and agenesis of right kidney in fetus diagnosed on autopsy.

\section{Case report}

Ultrasonography at 21 weeks of gestation in 33 years woman $\left(\mathrm{G}_{3} \mathrm{P}_{2} \mathrm{~L}_{2}\right)$ showed severe oligohydramnios and cystically enlarged left kidney of the fetus (Fig 1a). Right kidney was not visible. The couple asked for termination of pregnancy.

At autopsy, the male fetus weighed $330 \mathrm{gms}$ and crown rump length was $18 \mathrm{cms}$. Fetus showed characteristic Potter's facies showing prominent infraorbital folds, flattening of nasal bridge, widely separated eyes, receding chin with a depression below lower lip and low-set ears . The fetus also had bowing of the legs, inward rotation of the feet and spade-like hands. (Fig 1b). There was no encephalocoele, polydactyly or any other morphological abnormality seen. On opening the abdomen, left kidney was enlarged measuring $5.5 \times 3.5 \times 3 \mathrm{cms}$ and was diffusely cystic (Fig 1c). Cut surface of left kidney showed numerous cysts measuring 0.2 to $0.5 \mathrm{~cm}$ present throughout the renal parenchyma (Fig 1d). Right kidney was absent with absence of both ureters and urinary bladder (Fig 2a). No other gross anomaly of other organs were noted. Microscopy of the left kidney showed characteristic smooth muscle collars around primitive ducts (Fig 2b, 2c, 2d). All other organs including liver and lung were normal. With the findings of right renal agenesis and left sided multicystic dysplasia, the final diagnosis of renal adysplasia (Potter's type 2) was made. Subsequently the couple and their two daughters were screened and had normal genitourinary system on ultrasonography.

\section{Discussion}

The spectrum of congenital anomalies of the kidney and urinary tract (CAKUT) is estimated to affect approximately $10 \%$ of birth. ${ }^{[2]}$ CAKUT includes a wide range of kidney anomalies including aplasia, hypoplasia, adysplasia, multicystic dysplasia and ureteric anomalies such as megaureter, ureteropelvic junction obstruction or incompetence, duplex kidney/ureters, and anomalies of the bladder and urethra. ${ }^{[3,4]}$

Renal adysplasia is rare, occurring in only one per 10,000 births. Despite its being moreover a sporadic event, there is a M:F ratio of 2.5 to 1 and approximately $20-36 \%$ present with a familial recurrence, probably autosomal dominant mode of inheritance with incomplete penetrance and variable expression, termed as hereditary renal adysplasia. ${ }^{[5]}$ The genetic link between renal agenesis and dysplasia points to a common pathogenetic mechanism for these anomalies and perhaps relates to the degree of failure of the ureteric bud in its inductive function on the metanephric blastema. The dysplastic kidneys in renal adysplasia are usually rudimentary (renal aplasia) or multicystic. [1] Multicystic and aplastic kidneys are both severely malformed and differ in the degree of cyst formation. Multicystic kidney occur more often in males than in females, and the left kidney is affected more often than the right. ${ }^{[2]}$ The fetus in this case report was male and his left kidney was multicystic. 


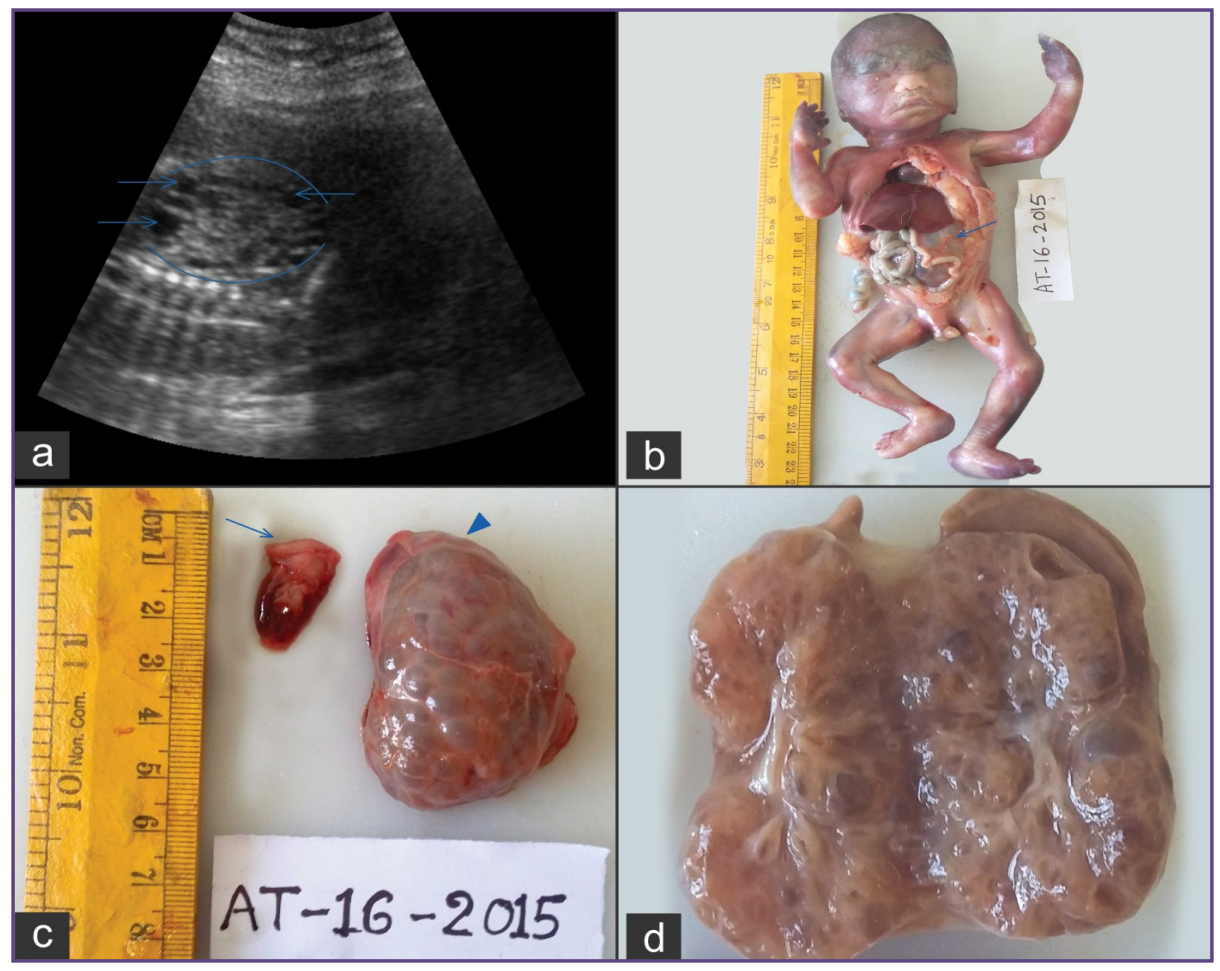

Fig. 1: a) Ultrasonography showing multicystic (arrows) left kidney in fetus, b) Fetus with Potter facies and buldged out left kidney (arrow) c) Bosselated left kidney, left adrenal (arrow head) and right adrenal (arrow) d) Left kidney showing multiple cysts.

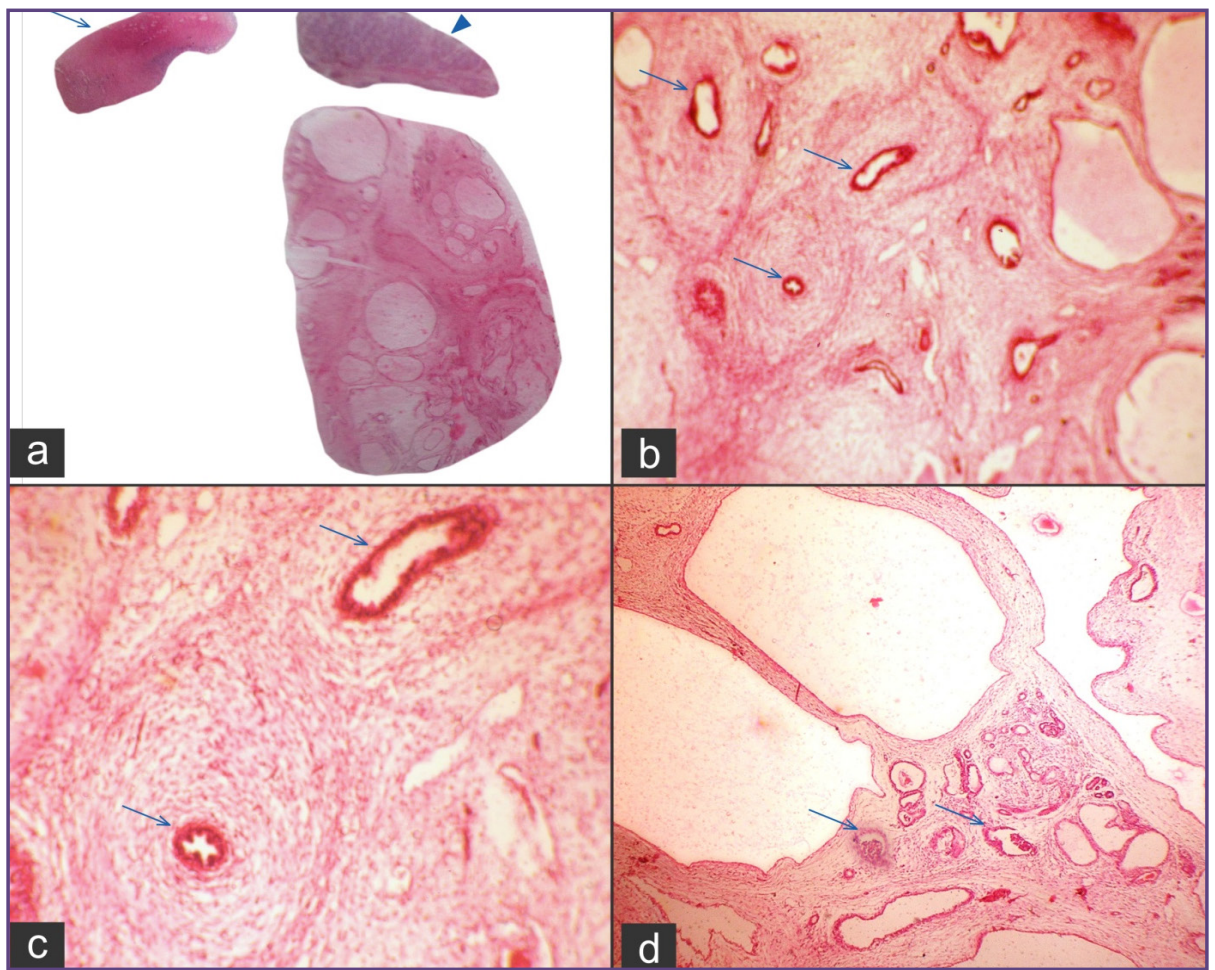

Fig. 2: a) Whole mount of left kidney with left adrenal (arrow head) and right adrenal (arrow) (H and E), Left kidney showing b) dysplastic tubules (arrow) surrounded by dysplastic stroma (H and E, x200), c) smooth muscle collars around primitive ducts (arrow) (H and E, x400), d) immature glomeruli (arrow) and cystic tubules (H and E, x200). 
The lack of fluid and the resultant pressure of the uterine wall on the developing fetus contribute to the accompanying abnormality collectively called as Potter's sequence. These include facial abnormalities (the Potter's facies), an excessive amount of skin and subcutaneous tissue, bowing of the legs, inward rotation of the feet and enlarged spade-like hands. The facial features include prominent infraorbital folds, flattening of nasal bridge, receding chin with a prominent depression below the lower lip and low set ears. ${ }^{[2,6]}$ In our case, bilateral malformed kidneys in fetus caused lack of fetal urine output with resultant severe oligohydramnios in utero leading to Potter's sequence.

The dysplastic kidney can either be larger or smaller than the normal and can be partly or diffusely cystic. The degree of dysplasia within the kidney can vary. It may affect cortex and medulla or predominantly medulla or it may involve only a segment of the kidney or the entire kidney. The characteristic histologic features are disrupted organization and primitive, poorly branched dysplastic tubules surrounded by poorly differentiated/metaplastic stroma in the form of fibromuscular collars. Metaplastic cartilage may be present in one third of the cases. ${ }^{[1,3]}$

Renal adysplasia can be associated with pulmonary hypoplasia and other anomalies, especially of the genital system. ${ }^{[7]}$ In our case, lung, liver and other organs were normal in the fetus. There were no digital anomalies, central nervous system abnormalities such as encephaloceles, cardiovascular defects or associated hepatic fibrosis. Hence the possibility of syndromes like Meckel's syndrome, Fraser syndrome, Di George syndrome were not considered. ${ }^{[1]}$ So we concluded this case to be non hereditary, non syndromic case of renal adysplasia.

Most cases of renal adysplasia are recognized at autopsy for investigation of perinatal death. Retrospective family studies have then revealed unilateral renal agenesis or dysplasia in parents or siblings in cases of hereditary renal adysplasia. The parents and siblings have an increased risk of having silent genitourinary malformation, therefore, all first degree relatives of affected children with renal agenesis or dysplasia should have an ultrasound to exclude a silent malformation. ${ }^{[8]}$

\section{Conclusion}

Renal adysplasia is often sporadic, diagnosed on prenatal or postnatal ultrasonography or at autopsy of fetuses or newborns. The parents must be made aware not only of inevitable fatal outcome for the fetus but also of the increased risk of recurrence in subsequent pregnancy.

\section{Abbreviation}

CAKUT: Congenital anomalies of the kidney and urinary tract

\section{Acknowledgement}

We are thankful to Dr Eranna Palled, Head of radiology department, for providing the imaging details.

\section{References}

1. Liapis H, Winyard P. Cystic diseases and developmental kidney defects. In: Jennette JC, Olson JL, Schwartz MM, Silva FG, editors. Heptinstall's Pathology of the kidney. 6th ed. Philadelphia: Lippincott Williams and Wilkins; 2007. p1292-306.

2. Lacson A, Bernstein J, Risdon RA, Gilbert-Barness E. Kidneys and urinary tract. In: Gilbert-Barness E, editor. Potter's Pathology of the Fetus, Infant and Child. 2nd ed. China: Mosby Elsevier; 2007. p1281-344.

3. Woolf AS, Price KL, Scambler PJ, Winyard PJD. Evolving concepts in human renal dysplasia. J Am Soc Nephrol 2004;15:998-1007.

4. Rodriguez MM. Congenital anomalies of the kidney and the urinary tract. Fetal and Pediatric Pathology 2014;33:293-320.

5. Stella A. Hereditary renal agenesis. Report of a case. Minerva Ginecol 1998; 50(6):255-9.

6. Sarkar S, Gupta SD, Barua M, Ghosh R, Mondal K, Chatterjee U, et al. Potter's sequence: A story of the rare, rarer and the rarest. Indian $\mathrm{J}$ Pathol Microbiol 2015;58:102-4.

7. Acein P, Galan F, Manchon I, Ruiz E, Acein M, Alcaraz LA. Hereditary renal adysplasia, pulmonary hypoplasia and Mayer-Rokitansky-Küster-Hauser (MRKH) syndrome: a case report. Orphanet Journal of Rare Diseases 2010;5:1-6.

8. Mcpherson E. Renal anomalies in families of individuals with congenital solitary kidney. Genetics in medicine 2007;9:298-302.

*Corresponding author:

Dr. Bhumika J. Bhandari, House No. 14, Jakali layout, Hemant Nagar, Keshwapur, Hubli, Karnataka, India- 580023

Phone: +9109844320387

Email: bhumikabhandari30@gmail.com

Financial or other Competing Interests: None.

Date of Submission : 27.03.2017

Date of Acceptance : 10.08.2017

Date of Publication : 12.12.2017 